\title{
Effect of Synthetic and Natural Zeolite on ASR Expansion
}

\author{
Suvimol Sujjavanich ${ }^{\mathrm{a}, *}$, Chanakorn Wongtanasarasin ${ }^{\mathrm{b}}$, and Paisan Kongkachuichay \\ Kasetsart University, 50 Ngamwongwan, Chatuchak, Bangkok 10900, Thailand \\ E-mail: afengsusa@ku.ac.th (Corresponding author), bprofessionalman_jc@hotmail.com
}

\begin{abstract}
The cation exchange capability (CEC), pozzolanic reaction, and filling effects are important keys of natural zeolite for mitigation of Alkali Silica Reaction (ASR), but variation of the zeolite's composition is a major problem when it is utilized. This may not be the case for synthetic zeolite. This paper presents the effects of natural and synthetic zeolite on Alkali Silica Reaction's expansion control. The percentage cement replacement of synthetic zeolite A (SZ) were 0.5, 1.0, 1.5, 2.5, 5,7.5, and 10 and ground natural zeolite, clinoptilolite (NZ), were 10 and 20. It was found that the large percentage replacement $(10-20 \%)$ changed behaviors of fresh and hardened mixtures significantly. Large replacements of SZ (i.e., 7.5 and 10\%) significantly reduced workability and compressive strength, and increased expansion. Slight reductions in expansion were found for the use of small percentage replacement $(\mathrm{SZ}<5.0 \%)$. Chemical analysis and strength reactivity index tests revealed the non-pozzolanic properties of synthetic zeolite, but not the ground natural one, NZ. The NZ exhibited both pozzolanic reactivity and the capability to significantly reduce expansion. At $20 \%$ replacement of NZ, the expansion significantly reduced to none at 14 days of acceleration and less than $0.02 \%$ at the longer duration of 28 days. It was confirmed that the high CEC of the studied synthetic zeolite is not the key factor for the effective mitigation for ASR.
\end{abstract}

Keywords: ASR, synthetic zeolite, natural zeolite, expansion, compressive strength.

ENGINEERING JOURNAL Volume 21 Issue 2

Received 14 March 2016

Accepted 4 October 2016

Published 31 March 2017

Online at http://www.engj.org/

DOI:10.4186/ej.2017.21.2.269 


\section{Introduction}

Awareness of the alkali-silica reaction (ASR), the chemical deterioration of concrete between certain types of aggregates and alkali of cement, has been significantly increased and of interest since the first was reported in 1940 [1]. However, this concern is just currently growing in the Thai construction industry, from the first reported ASR case in an infrastructure, seventy years later, in 2011 [2]. Some local aggregates from current industrial mines have recently been found to be potentially reactive, in addition to the stable good quality limestone that has been previously used. To deal with such an anticipated problem, there are needs for research in mitigation as well as the understanding mechanism of the local potential reactive materials and their behaviors [3]. Among several mitigation methods, the uses of different pozzolan have been widely and successfully reported for their effect on ASR prevention, the local moderate calcium oxide fly ash in Thailand is as well $[4,5]$. Among several pozzolans, zeolite is gaining of interest. Natural zeolite is a hydrated aluminosilicate with Si-O and Al-O tetrahedral bonded as a building unit. It has been widely reported as an effective pozzolan for concrete in strength and durability aspects due to its exchangeable cation content and the crystallinity in addition to pozzolanic reaction and filling effects [6-8]. The exchangeable alkali cation that contain in most zeolite or cation exchange capability (CEC) effectively altered the chemistry of cement pore solution. It strongly affected CSH product in concrete and sometimes be classified to lay between silica fume and fly ash, strongly than some other pozzolan [6, 9]. Partial cement replacement of natural zeolite has been reported to effectively reduce the expansion due to ASR [10-14]. The CEC was indicated as one important key among several for the effectiveness for ASR mitigation [15]. However, the typical problems of most pozzolan which influence their effectiveness and applications are the variations in compositions, sources. and the uniformity of the available materials. As other pozzolans, the variations in types and uncertain structures of the natural zeolite, which largely depend on sources and compositions of the material, are recognized.

The low cost as well as controllable quality and certain properties of synthetic zeolite, particular the capability to exchange the $\mathrm{Na}^{+}$and $\mathrm{K}^{+}$ions available in the mixture, the CEC and an expected less expansion risk from reactive aggregates are attractive factors for use in ASR mitigation. Therefore, this study aims to investigate the potential use of synthetic zeolite to control ASR expansion, based on the similar primary structure of both natural and synthetic zeolites. The high CEC of synthetic zeolite may indicate a high potential to adsorb alkali ions and possibly reduces the severity of the ASR problem. Thus, it is of interest to investigate the capability of available commercial synthetic zeolite A $\left(\mathrm{Na}_{2} \mathrm{O} \cdot \mathrm{Al}_{2} \mathrm{O}_{3} \cdot 2 \mathrm{SiO}_{2} \cdot 4 \cdot 5 \mathrm{H}_{2} \mathrm{O}\right)$ on both fresh and hardened concrete and compare to that of the natural zeolite, clinoptilolite $\left.\left(\mathrm{Na}_{4} \mathrm{~K}_{4}\right)\left(\mathrm{Al}_{8} \mathrm{Si}_{40} \mathrm{O}_{96}\right) \cdot 24 \mathrm{H}_{2} \mathrm{O}\right)$, for ASR mitigation.

\section{Materials and Experimental details}

\subsection{Materials}

The chemical compositions of Portland cement type I, commercial synthetic and natural zeolites, and local rhyolite aggregates in this study are investigated by using X-ray Fluorescence (XRF - PANalytical, Model; Axios (Standardless Program:Omnian)) and petrographic techniques. The aggregates from the central region of Thailand have unit weight of $1,482 \mathrm{~kg} / \mathrm{m}^{3}$, the bulk specific gravity of 2.67 , while the absorption and percentage of voids were $0.40 \%$ and $0.60 \%$, respectively, according to the test followed ASTMC $29 / \mathrm{C}$ $29 \mathrm{M}-97[16]$

The greenish natural zeolite in this study, clinoptilolite commercial grade type in Thailand(NZ), was ground to obtain the particle size smaller than $149 \mu \mathrm{m}$ with an average size of $20 \mu \mathrm{m}$, using wet sieve analysis on No.100 standard sieve and image processing. Since the effectiveness of large amount of cement replacement were widely reported [6,9], the percentages replacement of ground natural zeolite in this study were 10 and 20.

The white powder of commercial synthetic zeolite A (SZ), from PQ Chemical (Thailand) Co. Ltd. has a number of 98.84 on the Hunter L, a, b scale, a median particle size of $4.24 \mu \mathrm{m}$, and an average bulk density (untapped) of $314 \mathrm{~kg} / \mathrm{m}^{3}$. This powder has the cubical shape and the characteristics as shown in Fig. 1 and Table 1. An Atomic Absorption Spectrophotometer (GBC Scientific Equipment, model Avanta AAS) (Flame technique) was used to investigate $\mathrm{Na}^{+}$content in synthetic zeolite. The two-step procedure was conducted; firstly, the SZ of about $25 \%$ by weight was mixed within $\mathrm{NaOH} 5 \mathrm{mg} / 1$ solution and 
continuously stirred at room temperature for $24 \mathrm{~h}$, then filtered, and determined $\mathrm{Na}^{+}$content. The result was compared to that of the pure $\mathrm{NaOH}$ solution, without $\mathrm{SZ}$. The similar procedure was also conducted using distilled water instead of $\mathrm{NaOH}$ in the second step. The results were compared and verified with the previous results. Since the zeolite SZ was synthetic material, the percentages cement replacement of SZ in expansion test were small-0.5, 1.0, 1.5, 2.5, 5,7.5, and 10. The large difference of NZ's CEC (mg $\mathrm{CaCO}_{3}$ per $g$ of anhydrous zeolite) from those of SZ, conducting with the same technique and in the same laboratory was of interest. However, this value of natural zeolite differs from previous studies and depends on several factors such as framework structure, ion size and shape, ionic charge and concentration of the external electrolyte solution [17].

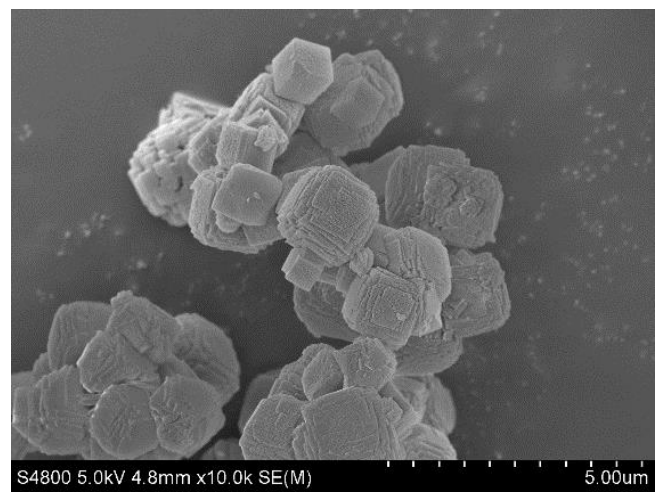

Fig. 1. Typical crystal shape of synthetic zeolite.

Table 1. Characteristics of synthetic zeolite A (SZ) and clinoptilolite(NZ).

\begin{tabular}{lcc}
\hline Characteristic & SZ & NZ \\
\hline $\mathrm{CEC}\left(\mathrm{mg} . \mathrm{CaCO}_{3}\right.$ per g. of anhydrous zeolite) & 281 & 11 \\
$\mathrm{pH}$ of $1 \%$ dispersion & 11.05 & $*$ \\
Wet sieve residue $(>325$ mesh) & 0.19 & $*$ \\
LOI: Moisture loss at $800^{\circ} \mathrm{C}(\%$ weight $)$ & 19.89 & 13.71 \\
\hline
\end{tabular}

$*$ Not doing analysis.

\subsection{Experimental Details}

\section{Consistency}

The effect of zeolite on water requirement and rheology was investigated using the mini slump method [18, 19]. The paste was prepared, using different percentages of cement replacement but with the amount of water kept constant for each test. The mini-slump cone was filled with the mixture, and the diameter of dispersed paste was measured at 1 min after vertically lifting the cone.

\section{Pozzolanic reactivity}

To investigate the pozzolanic behaviors of these zeolites, the $50 \mathrm{~mm}$ cubic mortar specimens of cementitious mixture were prepared according to ASTM C109, using simply method of strength reactivity index as suggested in ASTM C311-04 [20]. The control set, three sets of synthetic zeolite specimens (SZ with the percentage cement replacement of 2.5, 10, and 20) and two sets of two-percentage cement replacement of natural zeolite (NZ) of 10 and 20 were prepared. The constant water-to-binder ratio (cement or cement plus zeolite) of 0.485 was used for all mixes. The water cure at room temperature was used in this part. 


\section{Expansion behaviors}

Two sets of mortar bars, $(25 \times 25 \times 285 \mathrm{~mm})$, were prepared using fine crushed-graded rhyolite aggregates, according to suggested gradation and procedure in ASTM C1260-01 [21]. All samples were cured in $1 \mathrm{~N}$ $\mathrm{NaOH}$ solution at $80^{\circ} \mathrm{C}$ to accelerate the ASR reaction by providing abundant external alkalinity and a high-temperature environment. Different percentages of synthetic zeolite (SZ): 0, 0.5, 1.0, 1.5, 2.5, 5, 7.5, and 10 partially replaced cement in the first set. In the second set, natural zeolite (NZ) in percentages of 10 and 20 was used instead. The length changes of mortar bars were continuously measured at 14 and 28 days after immersion.

\section{Results}

The investigation results of chemical compositions of materials and thin section of rhyolite and SEM of natural zeolite are shown in Table 2 and Fig. 2.

Table 2. Chemical composition of materials.

\begin{tabular}{ccccc}
\hline Oxide (\% wt.) & Cement & Synthetic Zeolite & Natural Zeolite & Rhyolite [22] \\
\hline $\mathrm{Na} 2$ & 0.73 & 31.29 & 0.63 & 2.69 \\
$\mathrm{MgO}$ & 1.79 & 0.06 & 1.37 & 3.02 \\
$\mathrm{Al}_{2} \mathrm{O}_{3}$ & 6.06 & 30.39 & 13.01 & 17.39 \\
$\mathrm{SiO}_{2}$ & 29.61 & 38.13 & 78.51 & 56.49 \\
$\mathrm{P}_{2} \mathrm{O}_{5}$ & 0.10 & - & 0.02 & 0.22 \\
$\mathrm{SO}_{3}$ & 3.76 & 0.02 & 0.01 & 0.04 \\
$\mathrm{Cl}$ & 0.06 & 0.02 & 0.02 & - \\
$\mathrm{K} 2 \mathrm{O}$ & 0.62 & 0.03 & 1.39 & 4.03 \\
$\mathrm{CaO}$ & 53.51 & 0.02 & 3.39 & 8.55 \\
$\mathrm{TiO}_{2}$ & 0.30 & 0.01 & 0.18 & 0.86 \\
$\mathrm{MnO}$ & 0.07 & - & 0.03 & 0.16 \\
$\mathrm{Fe}_{2} \mathrm{O}_{3}$ & 3.30 & 0.02 & 1.29 & 6.51 \\
$\mathrm{NiO}$ & 0.01 & - & - & - \\
$\mathrm{CuO}$ & 0.01 & - & - & - \\
$\mathrm{ZnO}$ & 0.02 & - & 0.01 & - \\
$\mathrm{SrO}$ & 0.04 & - & 0.07 & - \\
$\mathrm{Total}$ & 99.99 & 99.99 & 99.93 & 99.96 \\
$\Sigma\left(\mathrm{SiO}_{2}, \mathrm{Al}_{2} \mathrm{O}_{3}, \mathrm{Fe}_{2} \mathrm{O}_{3}\right)$ & - & 68.54 & 92.81 & - \\
\hline
\end{tabular}
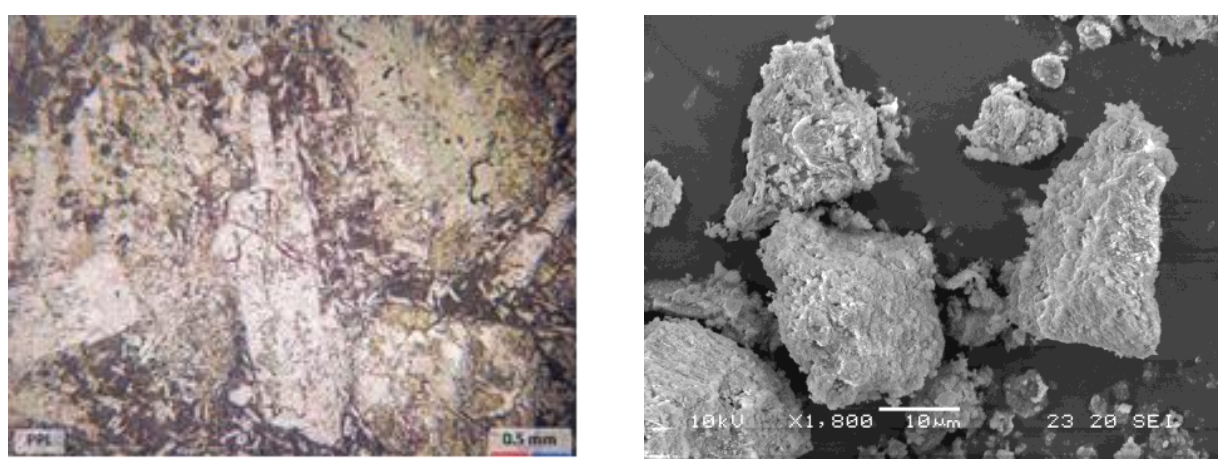

Fig. 2. (a) thin section of rhyolite [22]; (b)typical structure of natural zeolite.

The rhyolite aggregates composed of Albite, Quartz, Calcite, Chlorite, Feldspar, and Illite, and have a thin section as shown in Fig. 2(a). This rhyolite which has been identified as a potentially reactive aggregate [23] has a very fine grain mineral with an average phenocryst of $0.05-3 \mathrm{~mm}$ in size. 
For zeolites SZ, the value of $\mathrm{CEC}$ of 285 , based on $\mathrm{mg} \mathrm{CaCO}_{3}$ per $\mathrm{g}$ of anhydrous synthetic zeolite, was relatively high compared to that of 11 for the ground-natural one(NZ). The oxides of alkalis were also remarkably high compared to the low value of the natural one. Based on an Atomic Absorption Analysis, the detected sodium in the solution increased from $217 \mathrm{mg} / 1$ to $2,102 \mathrm{mg} / \mathrm{l}$ with similar observed trend using the water medium. Figure 3 shows the released water from both synthetic and natural zeolite at different temperature. The characteristic of higher released water of SZ than that of NZ, particular at high temperature was observed.

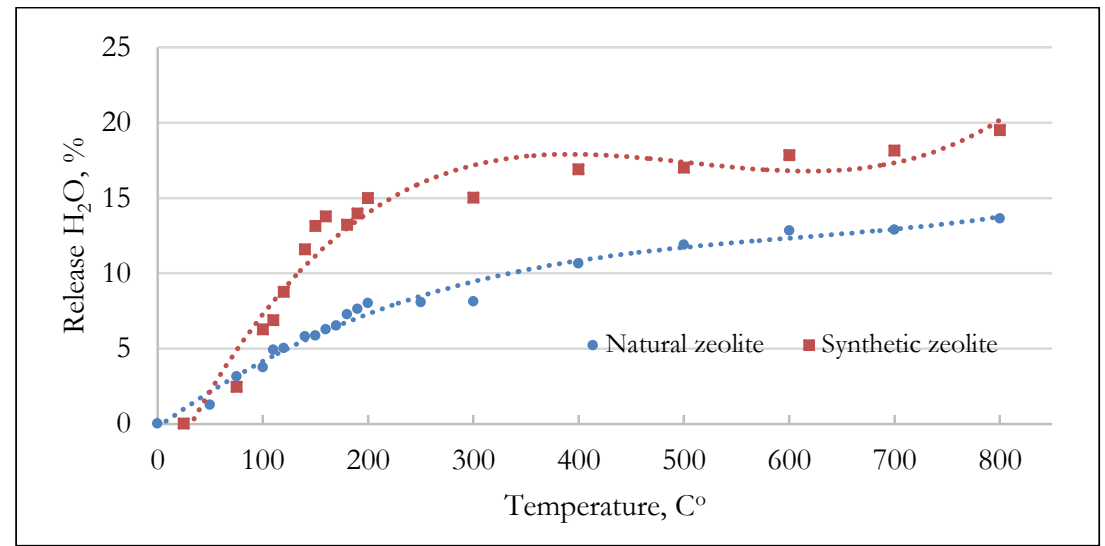

Fig. 3. Released water at different temperatures for both natural and synthetic zeolites.

\section{Consistency}

The percentage changes of the final spread diameter measurement of different mixtures from the original diameter were compared to that of a control as shown in Fig. 4. The replacement of SZ at a level of 10\% and higher obviously decreased the average percentage flow spread, compared to the slight changes obtained for those of sample with replacements less than 2.5\%. For the NZ, the decreased diameter is more significant for the $10 \%$ samples, but as the zeolite of both types was increased to $20 \%$; the strong reduction in flow spread fell in almost the same range.

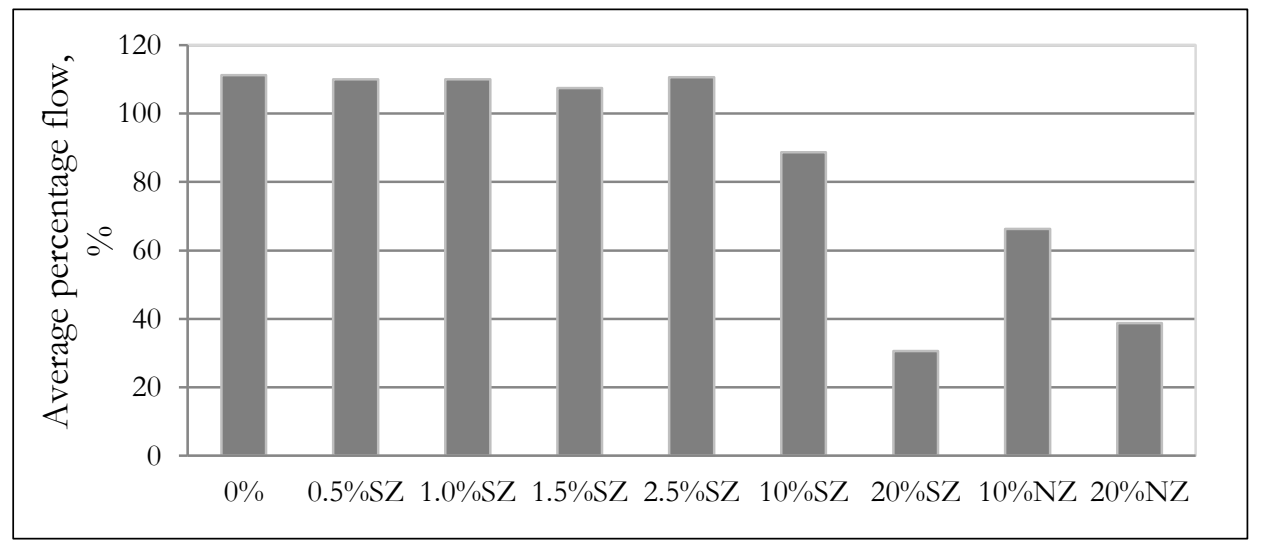

Fig. 4. Behavior on flow spread of mixtures.

\section{Pozzolanic reaction}

The simple strength reactivity index at age of 7 and 28 days was investigated using mortar samples. The results of average compressive strengths of samples, control samples $(0 \%)$, cement+synthetic zeolite $20 \%$ (SZ), and cement+natural zeolite 20\% (NZ)are shown in Fig. 5. Only slight changes are observed in SZ samples when a small amount of synthetic zeolite was used (2.5\%); the strength of $2.5 \% \mathrm{SZ}$ is close to 
those of the control cubes at both 7 and 28 days (4.6\% and 2.3\% reduction). For the high percentages of both types replacement, those being $10 \%$ and $20 \%(10 \% \mathrm{SZ}, 20 \% \mathrm{SZ})$, the compressive strength decreased by about $30 \%$ and $40 \%$ at 7 and 28 days, respectively.

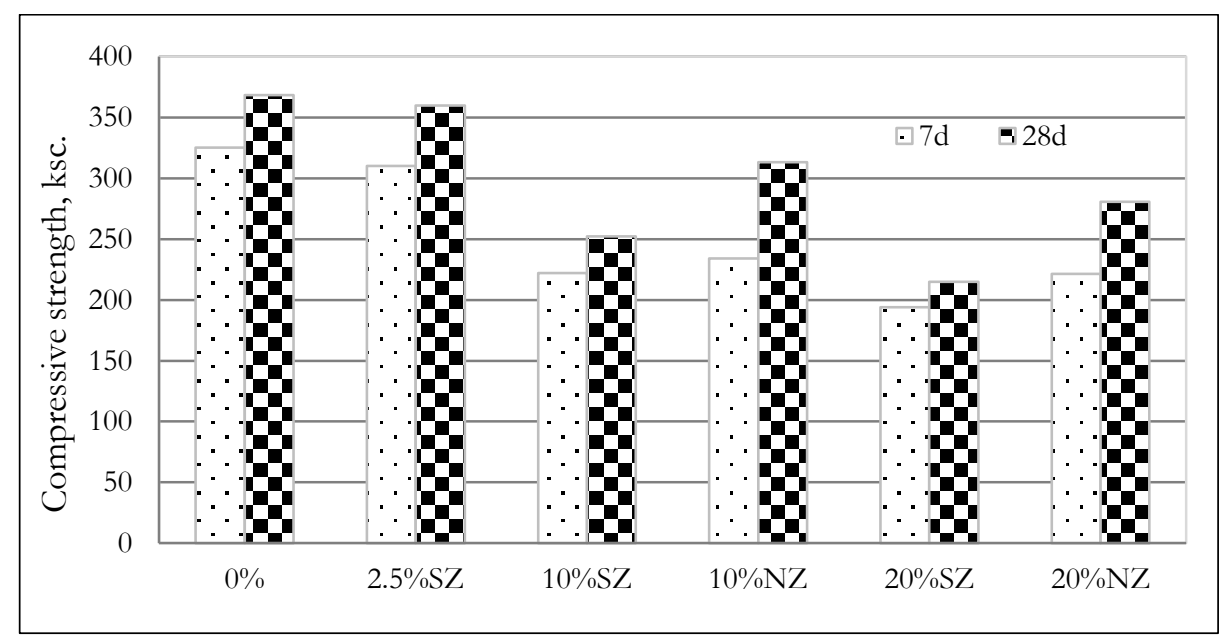

Fig. 5. Average compressive strength of mortar samples with different zeolite types and percentage replacement.

\section{Expansion}

The expansion of mortar bars is shown in Figs. 6 and 7. Average expansion at age of 14-28 days of the control $(0 \%)$ and those for varied percentage replacement of zeolite types $0.5 \% \mathrm{SZ}, 1.0 \% \mathrm{SZ}, 1.5 \% \mathrm{SZ}$, $2.5 \% \mathrm{SZ}, 5.0 \% \mathrm{SZ}, 7.5 \% \mathrm{SZ}, 10 \% \mathrm{SZ}, 10 \% \mathrm{NZ}$, and $20 \% \mathrm{NZ}$ were $0.186 \%, 0.174 \%, 0.172 \%, 0.160 \%, 0.179 \%$, $0.192 \%, 0.269 \%$, and $0.289 \%, 0.044 \%$ and $-0.003 \%$, respectively. In Fig. 6, the expansion behavior of samples with SZ can be clearly classified in three groups: the control, the large, and small replacement. Trends of continued increase until 28 days were observed for all mixes, except clinoptilolite mixes, for which the short- and long-term expansion were low to very low, particular for $20 \%$ replacement, as shown in Fig. 6. In this study, the addition of synthetic zeolite powder in small amounts (i.e., less than 2.5\%) slightly decreased expansion, but the same trend was not observed for large amounts (i.e., 7.5\% and higher), which showed severe expansion-even higher than that of the control.

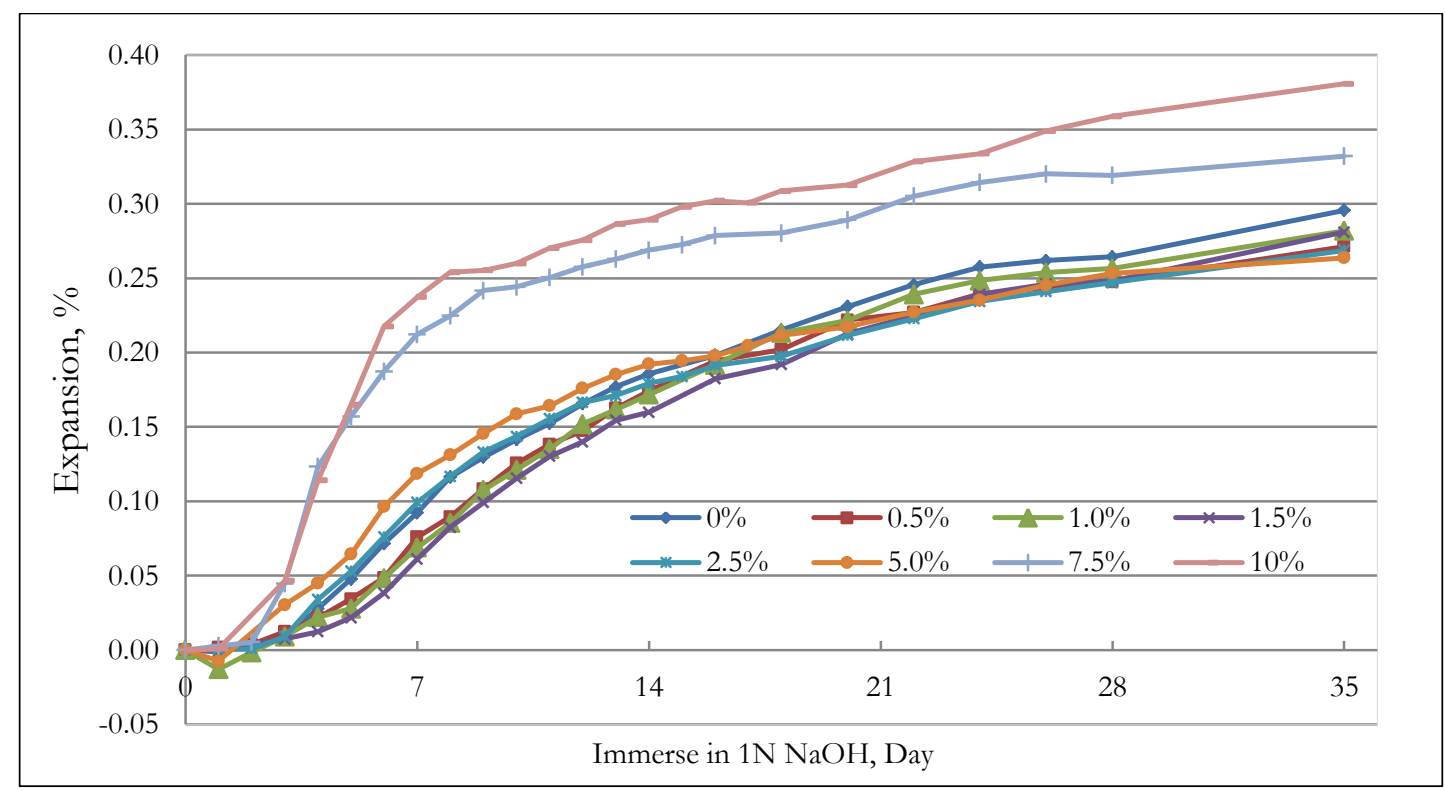

Fig. 6. Average expansion of mortar bars with synthetic zeolite and percentage replacement. 


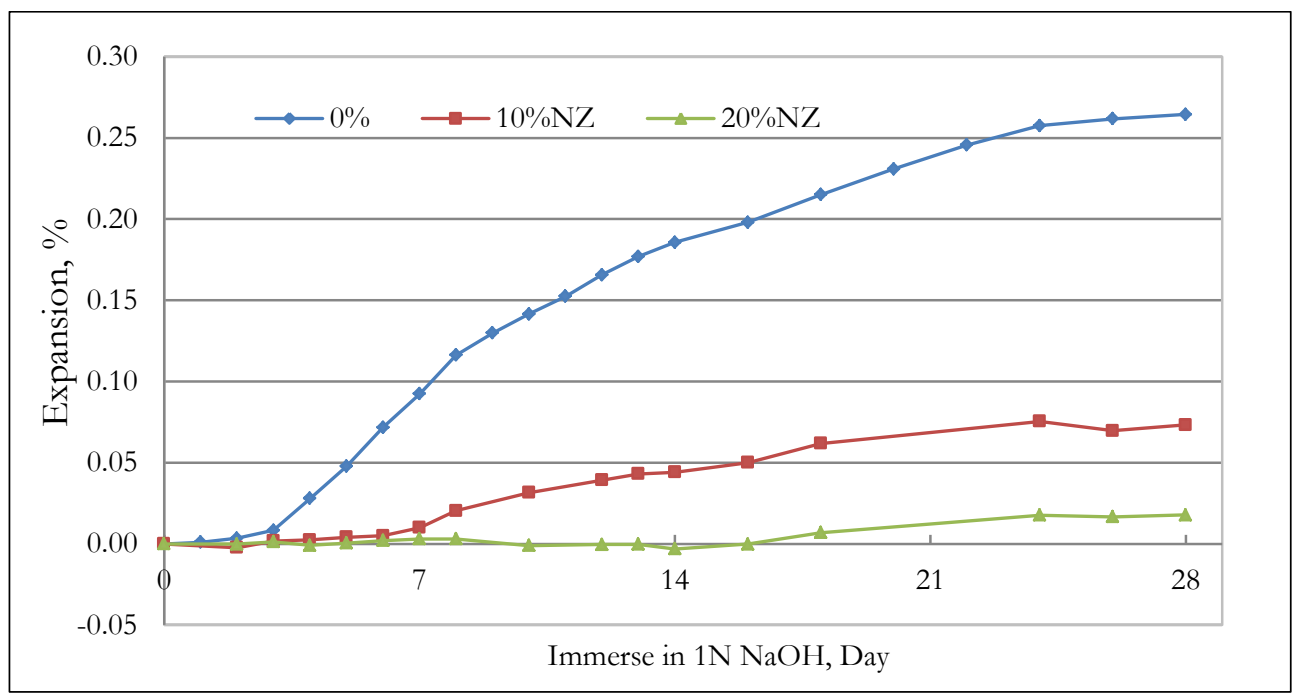

Fig. 7. Average expansion of mortar bars with natural zeolite.

\section{Discussion}

The results of Atomic absorption and the confirmed trend of the results from the second step showed the significant increase of sodium in the solution about 10 times from $217 \mathrm{mg} / 1$ (of NZ) to 2,102 mg/l (of SZ). These indicated a large amount of sodium ion from the studied SZ released into the solution. This may indicate the potential of extra supplied alkali to ASR expansion. The high silica and alumina content were in the range of typical natural zeolite. The ratio of $\mathrm{Si} / \mathrm{Al}$ of 5.32 implies that this material has less possibility to be damaged in a low $\mathrm{pH}$ environment $[24,25]$. On the other hand, the synthetic zeolite contains a much higher amount of $\mathrm{Al}$ (i.e., $\mathrm{Si} / \mathrm{Al}=1.10)$ than that of the natural one. This means that there are more $\left[\mathrm{AlO}_{4}\right]^{5-}$ tetrahedral units in its structure, and this creates a high amount of negative charges. Subsequently, this negative charge is neutralized by bounded $\mathrm{Na}^{+}[26]$, resulting in large $\mathrm{Na}+$ content detected in the synthetic zeolite, as shown in Table 2. The reported effects of an available alumina in alumina rich pozzolan on the capability of absorbing the reactive phases of the aggregates limited the dissolution of amorphous silica thus restricting ASR expansion [27]. However, the coupling effect of both low $\mathrm{Si} / \mathrm{Al}$ ratio and high released alkali of synthetic zeolite A has a questionable effect on ASR expansion, compared to the natural one NZ. Also, the higher amount of released water of synthetic zeolite in Fig. 3, compared to the natural one at the same temperature indicated the stronger capability to release water than that of the natural zeolite. This supplied internal moisture could be a main factor in making the ASR problem more acute and significant in the long term.

Considering the effects of these materials on the consistency of mixture, the high amount of very small size of SZ strongly impact flowability of the mixtures, particular at replacement of $20 \%$ indicates a significant potential of absorbing water of material. The samples with $10 \%$ of coarser NZ yielded the significant decreased in measured flow diameter compared to those of SZ, but not for $20 \%$. Although the strong reduction in flow spread fell in almost the same range, the particle shape and size of both zeolite types were responsible for these behaviors.

Focusing on strength activity indices, the synthetic zeolite (SZ) did not show pozzolanic reactivity for cements mortars strength improvement as were widely reported from natural zeolite [28], despite the fact that high silica and alumina content were observed in this study. However, the mixture with a small amount of synthetic zeolite $(2.5 \% \mathrm{SZ})$ had a slightly reduced compressive strength, particularly at longer ages due to the continued development of microstructure from cement hydration. The positive influence of imbibing water and the continued hydration on strength was not also clearly seen. In contrast, the natural zeolite showed better improved strength at 28 days, in the range of $0.76-0.85$ that of the control. The clear pozzolanic reactivity was observed.

Trends of continued increase until 28 days were observed for all mixes, except clinoptilolite mixes, for which the short- and long-term expansion were low to very low, particular for $20 \%$ replacement. In this study, the small amounts of addition synthetic zeolite powder (i.e., less than $2.5 \%$ ) slightly decreased 
expansion, but the same trend was not observed for large amounts (i.e., 7.5\% and higher), which showed severe expansion-even higher than that of the control sample. It was expected that the released alkali from synthetic zeolite, particularly for the large percentage replacement, may increase the amount of available alkalis in the samples and this can account for the large expansion of mortar bars with $7.5 \% \mathrm{SZ}$ and with $10 \% \mathrm{SZ}$, even at the short time of immersion. As the immersed time continued to 28 and 35 days all specimens severely expanded to exceed the criteria of $0.2 \%$. It is clear that, due to high $\mathrm{Na}$ content, the synthetic zeolite might not effectively reduce the ASR expansion when it was used in the as-received form. Nevertheless, the cation exchange capability of the used zeolite is much higher than that which has been reported in literature. On the other hand, the mixtures with the ground natural zeolite performed much better than those with the synthetic set. The expansion values at 14 days were 0.04 and $0.001 \%$ for the mixture with $10 \%$ and $20 \% \mathrm{NZ}$ addition, respectively. At the longer immersion time of 28 days, the continued expansions were still lower than $0.08 \%$. The $20 \%$ replacement showed the better results: less than $0.02 \%$. The mechanism of both materials may be different. The main involved factor on ASR expansion of the synthetic zeolite was the ability on cation exchange with the alkali ion in solution. Obviously, zeolite was expected to reduce available alkali ion that could react with reactive silica in aggregate. However, this was not the case for synthetic zeolite type A with high sodium content. The results of expansion test suggested the reasonable limit, for the effective ion exchange, of the amount of synthetic zeolite $(<7.5 \%)$ required to control alkali-silica reaction in this study. Opposed to the natural zeolite which the nature of pozzolanic behavior was an important factor on ASR expansion reduction although CEC is much lower than those of the synthetic one. In addition, the denser concrete matrix and strength improvement benefit expansion resistance.

It is clear that the hypothesis of the benefit of cation exchange between commercial zeolite and ASR gel was insignificant in this study and may need further investigation. This synthetic zeolite with high alkali content is non-pozzolanic material and the impact of both effects is clear in this study. The coarse particles of clinoptilolite zeolite in this study showed significant ASR expansion reduction, regardless of its low CEC.

\section{Conclusions}

From this study, important findings are summarized as follows:

1. The synthetic Zeolite A is non-pozzolanic material. The potential of later-released alkali and that of moisture were observed to be significant for SZ, and these may aggravate the ASR expansion due to resupplied sources for alkali and moisture in mortar samples.

2. A large amount of SZ replacement reduced the flow ability of mixtures significantly. Similar behavior was observed for natural zeolite, particularly at $20 \%$ replacement.

3. The expansion due to ASR can be slightly reduced by replacing cement with small amount of SZ in the range $0.5 \%-5.0 \%$, but not for a large percentage replacement. Remarkable expansion reduction capability of the natural zeolite with low CEC was confirmed, most especially a reduction to none (zero expansion) for $20 \%$ cement replacement.

4. Compared to that of control at both ages, the average compressive strength for synthetic zeolite A was reduced significantly as the percentage replacement increased. The pozzolanic reaction was not observed as in the case in which natural zeolite was used.

5. The benefit of the cation exchange capability of the synthetic zeolite on ASR mitigation is not clear and needs further study. The advantage of pozzolanic reactivity of the natural zeolite was clearly shown and overcame the effect of CEC in this study.

\section{Acknowledgement}

Partial funding support from the Faculty of Engineering, Kasetsart University, kind supports from The Siam Research and Innovation Co., Ltd. for some equipment in preparing aggregates and from PQ Chemicals (Thailand) Ltd. for the commercial synthetic zeolite and some tests are greatly appreciated. 


\section{References}

[1] T. E. Stanton, "The expansion of concrete through reaction between cement and aggregate," American Society of Civil Engineering, vol. 66, pp. 1781-1811, 1940.

[2] S. Sujjavanich, K. Won-in, W. Wongkamjan, and P. Dararutana, "The application of fluoresced gel for the first alkali silica reaction evidence in Thailand," Advanced Materials Research, vol. 368-373, pp. 613-616, 2012.

[3] P. Crucq, "Development of a method to measure the mechanical behavior of ASR gel," Microlab Civil Engineering and Geosciences, Delft University of Technology, Netherland, Rep. 9165641, 2005.

[4] C. Sangsuwan and S. Sujjavanich, "Effect of moderate calcium oxide fly ash on expansion of mortar bar due to Thai reactive aggregate," Engineering Journal, vol. 16, no. 3, pp. 101-107, 2012.

[5] S. Sujjavanich, C. Sangsuwan, K. Won-in, R. Guntapong, and B. Kubtitunhi, "Efficiency of lignite fly ash on expansion control of alkali aggregate reaction," in 5th Asian Concrete Federation International Conference, Pattaya, Thailand, 2012.

[6] C. S. Poon, L. Lam, S. C. Kou, and Z. S. Lin, "A study on hydration rate of natural zeolite blended cement pastes," Construction and Building Materials Journal, vol. 13, no. 8, pp. 427-432, 1999.

[7] M. Najimia, J. Sobhani, B. Ahmadi, and M. Shekarchi, "An experimental study on durability properties of concrete containing zeolite as a highly reactive natural pozzolan," Construction and Building Materials, vol. 35, pp. 1023-1033, 2012.

[8] R. Snellings, G. Mertens, Ö. Cizerb, and J. Elsen., "Early age hydration and pozzolanic reaction in natural zeolite blended cements: Reaction kinetics and products by in situ synchrotron X-ray powder diffraction," Cement and Concrete Research, vol. 40, no. 12, pp. 1704-1713, 2010.

[9] R. Snellings, G. Mertens, and J. Elsen, "Calorimetric evolution of the early pozzolanic reaction of natural zeolites," Journal of Thermal Analysis and Calorimetry, vol. 101, no. 1, pp. 97-105, 2010.

[10] X. X. Feng, N. Feng, and D. Han, "Effect of the composite of natural zeolite and fly ash on alkalisilica reaction," Journal of Wuhan University of Technology Mater. Sci. Ed, vol. 18, no. 4, pp. 93-96, 2003.

[11] R. Takata, S. Sato, T. Nonaka, H. Ogata, and K. Hattori, "Investigation on alkali-silica reaction utilizing waste glass in concrete and suppression effect by natural zeolite," in 29th Conference on Our World in Concrete and Structure, Singapore, 2004, pp. 523-528.

[12] D. Jana, "A new look to an pozzolan: Clinoptilolite in concrete," in 29th International Conference on Cement Microscopy, Quebec City, Canada, 2007, pp. 168-206.

[13] B. Ahmadi and M. Shekarchi, "Use of natural zeolite as a supplementary cementitious material," Cement and Concrete Composite, vol. 32, no. 2, pp. 134-141, 2010.

[14] T. Perraki and E. Kontori, S. Tsivilis, and G. Kalali, "The effect of zeolite on the properties and hydration of blend," Cement and Concrete Composite, vol. 32, no. 2, pp. 128-133, 2010.

[15] N. Feng and T. Hao, "Mechanism of natural zeolite power in preventing alkali silica reaction in concrete," Advanced in Cement Research, vol. 10, no. 3, pp. 101-108, 1989.

[16] American Society for Testing and Materials, Standard Test Method for Bulk Density ("Unit Weight") and Voids in Aggregate Concrete and Concrete Aggregates, Vol. Designation: C 29/C 29M - 97, PA, USA: ASTM Committee C-9 on Concrete and Concrete Aggregates, 1997.

[17] D. Kallo, "Applications of natural zeolites in water and wastewater treatment," in Natural Zeolites: Occurrence, Properties, Applications, D. L. Bish, Ed., 2001, pp. 519-550.

[18] D. R. Kantro, "Influence of water reducing admixtures on properties of cement paste a miniature slump test," Cement, Concrete and Aggregate, vol. 2, no. 2, pp. 95-102, 1980.

[19] J. Zhor and T. W. Bremmer, "Advances in evaluation of lignosulphonates and concrete admixtures," $A C I$, vol. 179, pp. 1011-1042, 1998.

[20] American Society for Testing and Materials, Standard Test Methods for Sampling and Testing Fly Ash or Natural Pozzolans for Use in Portland-Cement Concrete, Annual Book of ASTM Standards, vol. 04.02 Concrete and Aggregates Vol. Designation: C 311 - 04. PA, United States: ASTM International, 2004

[21] American Society for Testing and Materials, Standard Test Method for Potential Alkali Reactivity of Aggregates (Mortar-Bar Method), ASTM C 1260, PA, United States, 2003.

[22] S. Sujjavanich, K. Won-in, and C. Chaisuwan, "Final report: The problem of source mass and deterioration of the structure of alkaline silica in Thailand," Faulty of Engineering, Kasetsart University, Bangkok, 2013.

[23] T. Supachai, "Properties and effects of reinforced steel on expansion of ASR affected concrete," M. Eng. thesis, Dept. of Civil Engineering, Kasetsart University, Bangkok, Thailand, 2013. 
[24] Y. Yang, X. Zhenjian, C. Weizhong, and C. Min, "Distribution of water content in self-compacted high strength concrete due to water evaporation and self-desiccation," in $1^{\text {st }}$ International Symposium on Design, Performance and Use of self-consolidating Concrete, Changsha, China,2005.

[25] P. Palesa, E. M. Diale, I. Member, and Z. Josephat, "A study of South African natural zeolite properties and applications," in World Congress on Engineering and Computer Science, San Francisco, USA, 2011.

[26] A. Dyer, "Ion-exchange properties of zeolites and related materials," in Introduction to Zeolite Molecular Sieves. UK: Bath Press, 1988, p. 149.

[27] T. Chappex and K. L. Scrivener, "The influence of aluminium on the dissolution of amorphous silica and its relation to alkali silica reaction," Cement and Concrete Research, vol. 42, pp. 1645-1649, 2012.

[28] B. D. Ikotun and S. Ekolu, "Strength and durability effect of modified zeolite additive on concrete properties," Construction and Building Materials, vol. 24, pp. 749-757, 2010. 